\title{
If Anyone Should Be an Agent-Causalist, then Everyone Should Be AN AgENT-Causalist
}

\author{
Christopher Evan Franklin \\ forthcoming in Mind
}

\begin{abstract}
Nearly all defenses of the agent-causal theory of free will portray the theory as a distinctively libertarian one-a theory that only libertarians have reason to accept.

According to what I call 'the standard argument for the agent-causal theory of free will', the reason to embrace agent-causal libertarianism is that libertarians can solve the problem of enhanced control only if they furnish agents with the agent-causal power. In this way it is assumed that there is only reason to accept the agent-causal theory if there is reason to accept libertarianism. I aim to refute this claim. I will argue that the reasons we have for endorsing the agent-causal theory of free will are nonpartisan. The real reason for going agent-causal has nothing to do with determinism or indeterminism, but rather with avoiding reductionism about agency and the self. As we will see, if there is reason for libertarians to accept the agent-causal theory, there is just as much reason for compatibilists. It is in this sense that I contend that if anyone should be an agent-causalist, then everyone should be an agent-causalist.
\end{abstract}

\section{Introduction}

I aim to establish the following conditional: if anyone should be an agent-causalist, then everyone should be an agent-causalist. I use the term 'agent-causalist' to refer to a proponent of the following view:

Agent-causal theory of free will: an agent s's action $\varphi$ is directly free only if $s$ fundamentally causes $\varphi .^{1}$

\footnotetext{
${ }^{1} \mathrm{I}$ here assume a product view of action, on which an event is an action in virtue of its causal history. According to this account, agents cause their actions. Alternatively, proponents of component views of action contend that an event is an action in virtue of its internal causal structure. For example, O'Connor maintains that agents do not fundamentally cause free choices, but rather free choices consist in the agent's fundamentally causing 'the-coming-to-be-of-an-actiontriggering-intention-to-so-act' (2000, p. 94; cf. 2009, pp. 195-6). I am sympathetic to Clarke's (2003, p. 25) contention that nothing of substance as regards free will depends on which theory we adopt. But regardless, none of my arguments turn on these issues. I will continue, for ease, to employ a product view of action, even when discussing the views of those who endorse a component theory.

Another complicating factor is that a proponent of the agent-causal theory might allow for the possibility of directly free action that is not fundamentally caused by the agent, so long as the agent could have either fundamentally caused this action or have prevented this action from occurring by exercising his power to fundamentally cause another action. In such a case my statement of the agent-causal theory would need to be amended. I return to this issue in n. 36 below.
} 
A few words of clarification are in order. First, I do not draw a firm distinction between free will and free action. The notion of action in the contemporary philosophical literature has broadened to include, in addition to bodily actions, mental actions—-such as choice, effort, and attention. I will use the idea in this broadened manner. Second, it is common now to draw a distinction between directly and indirectly free actions. Directly free actions must satisfy some stringent set of demands, while indirectly free actions need not satisfy these demands, so long as they are suitably connected to (e.g. caused by) earlier directly free actions. Thus, proponents of the agent-causal theory of free will can allow for the possibility of free actions that do not fundamentally have substances among their immediate causal antecedents, so long as these free actions are suitably connected to other actions that do fundamentally have substances among their immediate causal antecedents. The focus of this paper will be restricted to directly free actions.

Third, the agent-causal theory of free will requires that agents cause their free actions fundamentally or irreducibly. Contrast this with the event-causal theory of free will, which also envisages agents as causes of their directly free actions, albeit not fundamentally:

Event-causal theory of free will: an agent $s$ 's action $\varphi$ is directly free if and only if certain $s$ involving mental states and events nondeviantly cause (in a special way) $\varphi{ }^{2}$

On this account, an agent's causing a directly free action wholly consists in certain mental states of, and events involving, the agent (e.g. his desires and beliefs) causing the action in the appropriate manner (Davidson 1963, 1971, 1973; Goldman 1970; Brand 1984; Bishop 1989; Mele 1992; Enç 2003). Event-causal theories of free will are reductionist: they seek to reduce the event of an agent's

\footnotetext{
${ }^{2} \mathrm{By}$ 'in a special way' I have in mind 'nondeterministically.' Libertarians who endorse the event-causal theory will require that the mental events and states that cause directly free actions do so nondeterministically (Kane 1996; Clarke 2003).

The qualification of nondeviance is required to exclude cases in which mental states bring about an event, but, intuitively, there is no action. For example, a spy's belief that if he does not blink his eyes at a certain time, then the mission will go poorly and his desire to see the mission succeed might so unnerve him that he blinks his eyes at the right time (a nervous twitch). This event is caused by his belief and desire, but it does not seem to qualify as an action, since it was brought about through a deviant causal path (Davidson 1973).
} 
bringing about a free action to states and events involving the agent bringing about the action. The agent-causal theory rejects this reductionism, affording the agent irreducible causal involvementcausal involvement that does not wholly consist in the causal involvement of mental states and events involving him. ${ }^{3}$ I will use 'the agent-causal power' to refer to the distinctive kind of power that agents possess who satisfy the agent-causal theory of free will.

Fourth, the scope of the agent-causal theory extends only to free action, not action per se. The agent-causal theory of free will is consistent with the following sufficient condition for action: an agent $s$ performs an action $\varphi$ if certain $s$-involving mental states and events nondeviantly cause $\varphi .{ }^{4}$ According to this condition, a thief's robbing a poor box counts as an action if the event of the thief robbing the poor box is caused, in a nondeviant manner, by the thiefs desire to increase his networth and his belief that he could realize this end by so acting. ${ }^{5}$ The proponent of the agent-causal theory of free will need only deny that this is enough for free action (O'Connor 2000; Clarke 2003). The fundamental difference between event-causal and agent-causal theories is that the former reduce the relevant agential activity (action, free will, self-governance, etc.) to the causal interplay among states and events involving the agent, while the latter requires the agent to be irreducibly causally involved. It is important to realize that we can have event-causal and agent-causal theories of different phenomena. We can have agent-causal theories of action, free will, self-governance, and so

\footnotetext{
${ }^{3}$ Defenders of the agent-causal theory of free will disagree about whether states and events also are casually involved in the production of free action. On Clarke's integrated agent-causal model, states and events are joint causes with the agent of free action (2003), while O'Connor denies them any such causal involvement in the production of free action (2000, 2009).

${ }^{4}$ Both O'Connor (2000) and Clarke (2003) explicitly concede that an event that is merely nondeviantly caused by apt mental states and events is an action. What they disagree about is whether causation by apt mental states and events is necessary for free action. O'Connor (2009) rejects it as a necessary condition, while on Clarke's integrated agent-causal theory he accepts this condition as necessary and sufficient. On Clarke's account, an event-even one fundamentally caused by the agent - is an action only if it is nondeviantly caused by apt mental states and events (see especially Clarke 2003, p. 136). Free action on Clarke's account must then be jointly caused by the agent and apt mental states and events. ${ }^{5}$ One important area of disagreement among proponents of the event-causal theory of action concern just which mental states and events must be among the causes of action. For important discussions of these issues see Brand 1979 and Mele 1992.
} 
forth. The same goes for event-causal theories. It is open then to philosophers to accept agent-

causal theories of some phenomena (e.g. self-governance), while accepting event-causal theories of other phenomena (e.g. action). We must be careful, then, to specify clearly what the theory we are discussing is a theory of. As my analysis makes clear, I am concerned with the agent-causal theory of free will.

It would be a colossal understatement to say that the agent-causal theory of free will is unpopular. Notwithstanding the ingenious make-over this theory has received at the hands of philosophers such as 'Timothy O’Connor (2000, 2005, 2009), Derk Pereboom (2001, 2004), and Randolph Clarke (2003), the theory continues to be perceived as deeply obscure (Bratman 2000; Enç 2003), explanatorily empty (Schlosser 2008), and scientifically primitive (Pereboom 2001). ${ }^{6}$ Some of the resistance to this view clearly stems from a failure to understand it. ${ }^{7}$ My aim in this essay is to assist in understanding the nature of the agent-causal theory-in particular the theoretical motivation there is for accepting it. Almost all defenses of the agent-causal theory of free will portray the reasons for endorsing the theory as belonging uniquely to libertarians. ${ }^{8}$ In this way it is

\footnotetext{
${ }^{6}$ Revealingly, both Clarke and Pereboom (have come to) reject the agent-causal theory of free will. Clarke argues that we ought to conclude that agent-causation is metaphysically impossible, though he does not think we can have 'a great deal of confidence' in this verdict (2003, p. 209). Pereboom concedes that agent-causation is metaphysically possible, but argues that we have empirical reasons for denying its actual existence (2001, pp. 79-88).

7 Witness Enç's assumption that the agent-causal theory is committed to substance dualism (2003, pp. 19-21) or the common mistake that the agent-causal theory requires there to be two distinct kinds of causal relations (Bishop 1986, p. 228; cf. Moore 2010, p. 30), rather than simply requiring one kind of causal relation that can take different kinds of entities as relata. This last point bears emphasizing. The agent-causal theory, as I envisage it, does not require the existence of two kinds of causal relations, but only requires that a single causal relation can take as relata two different metaphysical kinds, e.g. substances and events. On this point I follow Clarke 2003, pp. 186-93 (cf. O’Connor 2000, pp. 67-74).

${ }^{8}$ An important recent exception to this claim is Markosian 1999, 2012. Nelkin 2011 might be another exception, but it is unclear whether she accepts the agent-causal theory of free will as I define it. She argues that deterministic worlds allow for 'agent causation (understood as causation by a rational agent for reasons)' (2011, p. 90). There is no mention of agents fundamentally causing their actions, and thus it is unclear that this is an instance of the agent-causal theory as defined above. Further worries emerge when she discusses the possibility that claims about agent-causation can be reformulated in terms of claims about event-causation. She responds to this possibility as follows: 'However, even if there is no metaphysical difference, but simply two equally good ways of describing the world, the fact that agents can legitimately be said to be causes, brings back the agent into the picture of action' (2011, p. 91; emphasis mine). This seems to give up on agent-causation. There is a metaphysical difference between agents who satisfy the agent causal theory and those who merely satisfy the event-causal theory. Moreover, contending that agents are 'legitimate' causes does not
} 
assumed that there is only reason to accept the agent causal theory if there is reason to accept libertarianism. I aim to refute this claim. ${ }^{9}$ I will argue that the reasons we have for endorsing the agent-causal theory of free will are nonpartisan. If there is reason for libertarians to accept this theory, there is just as much reason for compatibilists. It is in this sense that I contend that if anyone should be an agent-causalist, then everyone should be an agent-causalist. Although my aim is not to defend the agent-causal theory per se, I believe my conclusion will place the theory in a more attractive light. First, libertarianism enjoys little more popularity than the agent-causal theory, and so for those philosophers who reject the agent-causal theory only because they reject libertarianism, we will have removed a rather large obstacle to accepting the agent-causal theory. Second, by isolating the core reasons we have for accepting this theory, we will, I suggest, be in a better position to appreciate its merits.

I begin with a negative defense of this conclusion. In section 2 I present what I call 'the standard argument for the agent-causal theory of free will' and in section 3 I show that this argument, an argument that renders the agent-causal theory a distinctively libertarian one, is flawed. In section 4 I explain the true theoretical motivation for endorsing the agent-causal theory and show that these reasons are nonpartisan. In section 5 I conclude by way of reflection on how these conclusions affect the case for agent-causal libertarianism.

\section{The Standard Argument for the Agent-Causal Theory of Free Will}

amount to claiming that they are fundamental causes. Event-causal theories will (or at least should) allow that we can 'legitimately' say that agents are causes; what they deny is that agents are fundamental causes.

${ }_{9}$ Markosian (1999) also seeks to refute this claim by arguing that the most plausible version of the agent-causal theory is in fact a compatibilist one. I disagree with Markosian, though I will not press the point here. While we both defend the conclusion that the reasons for accepting the agent-causal theory are not uniquely libertarian in nature, we provide importantly different arguments for this conclusion. The most notable difference is that my argument will not tilt us toward or away from either compatibilism or libertarianism. The main reason for accepting the agent-causal theory, I contend, is thoroughly nonpartisan. 
The standard argument for the agent-causal theory of free will consists of three argumentative steps:

(i) that compatibilism is false; (ii) that event-causal libertarianism cannot secure enhanced control vis-

$\grave{a}$-vis event-causal compatibilism, since the only necessary difference between these theories is that

the former requires the presence of indeterminism and indeterminism cannot be control

enhancing; ${ }^{10}$ and (iii) that furnishing agents with the agent-causal power provides them with more

control than is possible on compatibilist accounts. ${ }^{11}$ Let us consider these steps in turn. The

argument begins by contending that compatibilism is false. If all of our actions are the inevitable

consequences of the past and laws of nature, then, so the thought goes, we are not the true sources

of our actions or we cannot do otherwise (or both), and therefore we are not free. ${ }^{12}$ The conclusion

of the first step of the standard argument is that indeterminism is necessary for free will. So right

from the start the standard argument for the agent-causal theory takes place within an

incompatibilist framework. The next steps in the argument aim to show how best to construct a

model of free will given our incompatibilism.

\footnotetext{
10 The claim that 'indeterminism is control enhancing' for present purposes can be read either as the claim that 'indeterminism in and of itself is control enhancing' or 'indeterminism (at least when suitably located) entails the presence of control-enhancing features.' One might deny that mere indeterminism (even when suitably located) is control-enhancing and yet argue that if indeterminism is, e.g., located at the moment of choice, then the presence of indeterminism entails the presence of some other control-enhancing feature, such as the ability or opportunity to do otherwise. For ease, I will not distinguish these two readings since nothing of present interest turns on which reading we endorse.

11 The standard argument for the agent-causal theory of free will is endorsed by O'Connor (1993, 1995b, 2000, 2005, 2009), Clarke (1995, 2000, 2003), and Pereboom (2001, 2004, 2007), though the precise details in these author's presentations of the argument differ (sometimes in important ways). Chisholm (1966) may also have endorsed this argument, though he says too little for us to decide the matter one way or another. See n. 15 below for further discussion of this point. Important exceptions to this rule are Taylor (1966) and Steward (2012), both of whom argue that action itself requires that agents be fundamental causes. An important difference between their theories is that Taylor thinks that agent-causation is compatible with determinism, while Steward seems to deny this (2012, pp. 54-69). In effect, then, Steward's argument for the agent-causal theory of action (rather than free action) also ends up making the reasons for going agent-causal partisan: we only have reason for accepting the agent-causal theory of action if we have reasons for accepting incompatibilism about action and determinism. I return to these issues in $\mathrm{n}$. 17 below.

12 Incompatibilists offer different arguments for their view and also contend that different aspects of free agency are incompatible with determinism. Some contend that determinism is incompatible with free will because it is incompatible with sourcehood (Stump 1999; Zagzebski 2000; Pereboom 2001), some contend that determinism is incompatible with free will because it is incompatible with the ability or opportunity to do otherwise (van Inwagen 1983; Ginet 1990; Fischer 1994), and others maintain that it is incompatible with both the ability/opportunity to do otherwise and sourcehood (Kane 1996). These differences in their arguments do not affect steps 2 and 3 and thus I will ignore them.
} 
The second step seeks to show that event-causal libertarianism falls prey to the problem of enhanced control — the problem of explaining how libertarian models of freedom secure more control than rival compatibilist models. Libertarians argue that agents in deterministic worlds are not free because they lack the necessary degree of control for freedom. It is incumbent upon them, then, to explain how agents in nondeterministic worlds can possess an enhanced degree of control relative to compatibilist accounts. Many have argued that event-causal libertarians cannot discharge this explanatory burden (Watson 1999, pp. 198-207; O’Connor 2000, pp. 27-42; Pereboom 2001, pp. 41-54; Clarke 2003, pp. 95-107). These models of free will endorse the event-causal theory of action and augment it with a variety of further conditions in attempt to transform the event-causal theory of action into a theory of free will. But these supplementations notwithstanding, the only necessary difference between event-causal libertarianism and compatibilism-the only condition that eventcausal libertarianism requires that compatibilism cannot require-is that the former requires that some actions be undetermined. ${ }^{13}$ Therefore, it appears that if event-causal libertarianism secures enhanced control vis-à-vis event-causal compatibilism, it does so in virtue of requiring the existence of indeterminism. But the contention that indeterminism can enhance control has been widely rejected (Watson 1999, p. 206; Clarke 2003, p. 105; O’Connor 2009, p. 192). Gary Watson (1999, p. 203) likens the idea to a kind of alchemy — trying to get gold from straw.

The conclusion drawn by many is that event-causal libertarianism does not secure enhanced control with respect to compatibilism. According to Clarke, this is because:

The active control that is exercised on [the event-causal libertarian view] is just the same as that exercised on an event-causal compatibilist account. The type of libertarian view in

\footnotetext{
13 There are often other differences between libertarianism and compatibilism. Consider Kane's (1996) libertarian account on which self-forming actions play a central role. Although, to my knowledge, no compatibilist requires the existence of self-forming actions, they could, and the only necessary difference between their account of self-forming actions and Kane's is that they would not require that these actions be undetermined. Hence, although there are contingent differences between event-causal libertarianism and compatibilism, the only necessary difference is that event-causal libertarianism requires that some actions be undetermined. Or so the standard argument goes.
} 
question fails to secure the agent's exercise of any further positive powers to causally

influence which of the alternative courses of events that are open will become actual. (2003, p. 105)

Given that the only necessary difference between event-causal libertarianism and event-causal compatibilism is that the former theory requires the presence of indeterminism, and given that indeterminism cannot enhance control (after all the presence of indeterminism does not furnish agents with any 'further positive powers'), event-causal libertarianism fails to secure enhanced control. ${ }^{14}$

The conclusion that event-causal libertarians cannot secure enhanced control is sometimes defended by arguing that event-causal libertarianism is susceptible to the problem of luck. Consider the following passages from O'Connor and Pereboom:

A prima facie problem for [event-causal libertarianism] is to explain how the agent directly controls the outcome in a given case. There are objective probabilities corresponding to each of the possibilities, but within those fixed parameters, which choice occurs on a given occasion seems, as far as the agent's direct control goes, a matter of chance. (O'Connor 2000, p. xiii)

With the causal role of the antecedent conditions already give, it remains open whether the decision will occur, and whether it will is not settled by anything about the agent .... So whether the decision will occur or not is, in this sense, a matter of luck. (Pereboom 2007, p. 102)

\footnotetext{
${ }^{14}$ In Franklin 2011 I argue that, despite these philosophers' contention, event-causal libertarianism can solve the problem of enhanced control. If this conclusion is sound, then we already have reason for rejecting the standard argument for the agent-causal theory of free will. Below I will offer additional support for concluding that the standard argument is a failure: namely that the agent-causal theory lacks distinctive resources for solving the problem of enhanced control.
} 
Both O'Connor and Pereboom employ these conclusions about event-causal libertarianism to motivate an adoption of agent-causal libertarianism, and so it may seem that they think agentcausation is needed to help with the problem of luck rather than the problem of enhanced control. Consequently, it may seem like there is a second widely endorsed argument for the agent-causal theory, distinct from the one presented above. But we must be careful here. What I am calling the standard argument for the agent-causal theory contends that while event-causal libertarianism secures no less control than event-causal compatibilism, it also secures no more control. If O'Connor and Pereboom's arguments for the agent-causal theory that we are now considering defend this same point - if they also contend that the main problem with event-causal libertarianism is that it fails to secure any more control than rival compatibilist accounts- then there is merely a verbal difference between the standard argument and O’Connor and Pereboom's arguments. And indeed this is exactly what we find. This is particularly clear in the case of Pereboom. As he begins to defend his argument, he grants 'for the purposes of argument, that [event-causal libertarianism] allows for as much control as does compatibilism .... However, following Randolph Clarke's suggestion ... the concern is that if decisions were indeterministic events, then agents would have no more control over their actions than they would if determinism were true ..." (Pereboom 2007, pp. 106-7). Pereboom's reference to Clarke is decisive for establishing that he is not offering a distinct kind of argument (even if there are other important differences in the details): the argument (which Pereboom calls the 'disappearing agent argument') is that event-causal libertarianism, merely by adding indeterminism, fails to secure any more control than compatibilism.

The same is true of O'Connor, though the point is less clear. O'Connor has been running this kind of argument against event-causal libertarianism for nearly twenty years (1993, 2000, 2005, 2009). Consider his presentation of the argument in his recent article defending the agent-causal theory: 
However, according to many critics (myself among them), indeterminist event-causal approaches falter just here, in the fact that the free control they posit is secured by an absence, a removal of a condition (causal determination) suggested by the manifestly inadequate varieties of compatibilism. If there is no means by which I can take advantage of this looser connectivity in the flow of events, its presence can't confer a greater kind of control, one that inter alia grounds moral responsibility for the action and its consequences. (2009, p. 192) Here again the focus is on event-causal libertarianism's supposed failure to secure more control than compatibilism, and so O'Connor also seems to endorse the standard argument for the agent-causal theory.

The second argumentative step in the standard argument for the agent-causal theory of free will has various formulations, but the various formulations all drive home the same point: eventcausal libertarianism fails because it fails to furnish agents with any more control than is possible on compatibilist models of free will. The third and final step contends that unlike event-causal libertarianism, agent-causal libertarianism does secure enhanced control. Clarke argues that this model solves the problem of enhanced control because 'such an account provides ... also the exercise by the agent of a causal power (to influence which open alternative will be made actual) that is not secured by compatibilist views ... ' (2003, p. 134; cf. Watson 1999; O’Connor 2000, 2009; Pereboom 2001, 2004, 2007). Whereas the only difference between event-causal libertarianism and compatibilism is that the former requires the presence of indeterminism, agent-causal libertarianism, in addition to requiring the presence of indeterminism, also furnishes agents with the agent-causal power-a power that agents lack on compatibilism. What then must we do to construct a libertarian account of free will that affords agents more control than is possible on compatibilist accounts? We 
must furnish them with the agent-causal power, the power to fundamentally cause their actions. This is the standard argument for the agent-causal theory of free will. ${ }^{15}$

\section{Why the Standard Argument for the Agent-Causal Theory of Free Will Fails}

I will now argue that the standard argument for the agent-causal theory fails. The crucial assumption of the standard argument is that agents in deterministic worlds cannot possess or exercises the agent-causal power. To appreciate the need for the argument to make this assumption, suppose that agents in deterministic worlds can possess the agent-causal power. Then, while Clarke and others may be correct that agent-causal libertarianism secures more control than event-causal compatibilism, this is not the relevant comparison. ${ }^{16}$ What needs also to be shown is that agent-causal libertarianism secures more control than agent-causal compatibilism. If possession of the agent-causal power is compatible with determinism, and if possession of the agent-causal power is needed for freedom and responsibility, then compatibilists can help themselves to this condition and construct compatibilist accounts of the agent-causal theory. But now when we make the comparison between theories, agent-causal libertarianism appears to run into the same problem as event-causal libertarianism. Recall that the standard argument contends that the mere addition of indeterminism to event-causal libertarianism is insufficient to transform an unfree agent into a free agent because indeterminism cannot enhance control. But assuming that agents' possessing the agent-causal power

\footnotetext{
15 Besides Taylor 1966, the only other prominent defender of the agent-causal theory who might be an exception to the rule is Chisholm 1966. Chisholm defends the agent-causal theory by first arguing that agents in deterministic worlds cannot be free and then by arguing that on an nondeterministic view of action, which Chisholm (wrongly) assumes requires that actions be uncaused, it is clear that agents are not free. But he says precious little about how the argument is to be developed on the nondeterministic horn. If the problem with indeterminism is that it affords agents no more control than in deterministic worlds, then Chisholm adopts the standard argument. But Chisholm simply does not say enough to allow us to confidently decide this point.

${ }^{16}$ Clarke actually does concede that logical and causal determinism are compatible with the existence of the agent-causal power (see Clarke 2003, pp. 163-4, 181-3). My claim here is that the success of the argument requires us to assume that possessing or exercising the agent-causal power is incompatible with determinism. I will explain below how these concessions make trouble for Clarke.
} 
is compatible with determinism, then just as the only necessary difference between event-causal

libertarianism and event-causal compatibilism is that the former requires indeterminism, so also the

only necessary difference between agent-causal libertarianism and agent-causal compatibilism is that

the former requires indeterminism. And if the mere addition of indeterminism in event-causal

libertarianism was insufficient to transform an unfree agent into a free agent because indeterminism

cannot enhance control, then the mere addition of indeterminism to agent-causal libertarianism is

also insufficient to transform an unfree agent into a free agent. Therefore, if agents in deterministic

worlds can possess the agent-causal power, the standard argument for the agent-causal theory of free

will fails. ${ }^{17}$

I will now argue that this is indeed a possibility: agents in worlds where either logical or

causal determinism obtains can possess and exercise the agent-causal power. I define these different species of determinism as follows:

Logical Determinism: logical determinism obtains in a possible world $w$ if and only if for every possible world $w^{*}$ that has exactly the same laws of nature as $w$ and is exactly like $w$ at any one point of time, $w^{*}$ is exactly like $w$ at every point of time. (Earman 1986, p. 13) $)^{18}$

\footnotetext{
17 Similar problems confront Steward's argument that agency requires the existence of indeterminism. Her argument begins from the assumption that being an agent requires that one possess the power to settle. Let us grant this assumption for the sake of argument. What I want to call attention to is that her argument (2012, pp. 54-69) that an agent's exercise of the power to settle some question (e.g. whether to $\varphi$ ) requires the existence of indeterminism assumes that the agent-causal power is incompatible with determinism. She defends the putative connection between exercising the power to settle and indeterminism by arguing that there is no viable event-causal model of settling, and thus we must accept an agent-causal model if we are to build a viable model of agency. But this shows that the power to settle requires the existence of indeterminism only if the agent-causal power is incompatible with determinism: for if the agent-causal power is compatible with determinism, and if exercising the agent-causal power is really required for exercising the power to settle, then compatibilists can simply adopt the agent-causal model and construct an agent-causal compatibilist theory of agency (and free will). Steward's argument that agency is incompatible with determinism, like the standard argument for the agent-causal theory of free will, depends on the assumption that possessing and exercising the agentcausal power is incompatible with determinism, and thus Steward's argument, like the standard argument for the agentcausal theory, fails.

${ }^{18}$ I use the name 'logical determinism' merely to draw a contrast with 'causal determinism'. Logical determinism is not to be confused with fatalism.
} 
Causal Determinism: causal determinism obtains in a possible world $w$ if and only if for every event $e$ (except perhaps those at the very beginning of time), there is some event $e^{*}$ that causes $e$, and for every possible world $w^{*}$ that shares all and only the same laws and past as $w$, if $e^{*}$ occurs, then $e^{*}$ causes $e$ in $w^{*}$. (Clarke 2003, p. 4)

Let us begin by considering logical determinism. In order to try to accommodate the possibility of reasons-explanations, it is common for defenders of the agent-causal theory to allow probabilities to be associated with how an agent exercises his agent-causal power (O'Connor 2000, 2009; Clarke 2003). Suppose Jones, a recent high-school graduate who satisfies the agent-causal theory, is deliberating about whether to attend Yale or Harvard. Defenders of the agent-causal theory contend that Jones's possessing various motives (desires, beliefs, cares, etc.) relevant to attending each school structures probabilities for his exercising his agent-causal power in making either decision. Let us suppose that given Jones's motives, the probability associated with his exercising his agent-causal power to choose to attend Yale is 0.7 , and suppose that Jones exercises his agent-causal power to make this decision. We can then explain, or so claim proponents of the agent-causal theory, why Jones made this decision by citing his motives that raised the probability of his exercising his agentcausal power to decide to attend Yale to 0.7 . Given our present aims, we need not worry whether these explanations are defective in some sense; the point here is that if we can conceive of probabilities being associated with how agents exercise their agent-causal power, we should have little trouble conceiving of the associated probabilities being $1 .{ }^{19}$ Someone who wishes to argue that the agent-causal power is incompatible with logical determinism must argue that while there can be probabilities associated with how this power is exercised, all such probabilities must be less than 1. But why can we not just as readily conceive of Jones's background, upbringing, current

\footnotetext{
${ }^{19}$ See O’Connor $(2000,2009)$ who defends this account of reason-explanations. Clarke (2003, pp. 138-44) criticizes O'Connor's account of and offers an alternative model of reasons-explanation.
} 
environment, and motivational economy being such that the probability associated with his exercising his agent-causal power to decide to attend Yale is 1? Given that the probabilities of exercises of the agent-causal power can be structured by an agent's motives (and presumably other factors), we need a reason to think that the exercises of the agent-causal power can only have associated with them probabilities of less than 1 . But it is hard to fathom what reason we might have for thinking this — and certainly none has been offered by defenders of the agent-causal theory. ${ }^{20} \mathrm{I}$ conclude, therefore, that agents can possess and exercise the agent-causal power in worlds where logical determinism obtains. ${ }^{21}$

While this conclusion alone might have force to undermine the standard argument for the agent-causal theory of free will, some might argue that what really bothers incompatibilists is not logical determinism, but causal determinism (Stump 1999; Zagzebski 2000; Pereboom 2001). And so long as we might have reason to think that the agent-causal power is incompatible with causal determinism, defenders of the standard argument might seek refuge there. However, there is no more reason to think that the agent-causal power is incompatible with causal than logical determinism. Consider Jones’s causing his decision to attend Yale. Some defenders of the standard argument contend not that the decision to attend Yale could not be causally determined, but rather

\footnotetext{
${ }^{20}$ Could one respond as follows: the agent-causal power is 'the power for an agent to fundamentally cause which of two causally possible things happens (whether this be deciding between two options or simply not making any decision)'? For example, John Duns Scotus seemed to hold that the agent-causal power has a 'hard-wired' option of doing nothing — that is, not deciding a matter one way or the other, just then. All of my motives might point to willing to $\varphi$, but, says Scotus, I could refrain from deciding to $\varphi$ and this, it may seem, does not require that I have any particular antecedent motive to refrain from deciding at that moment. One could so define the agent-causal power-one could just stipulate that the agent-causal power is inherently nondeterministic-but this move will be of no help in patching up the standard argument. For although given this definition of the agent-causal power, no compatibilist account can make use of the agent-causal power, there will be a very similar power that compatibilists can make use of. Call this 'the agentcausal power*': the power for an agent to fundamentally cause her action. The only difference between an account requiring that agents possess the agent-causal power and accounts requiring merely that agents possess the agent-causal power* is that the former account requires the existence of indeterminism. So agent-causal libertarianism will still fare no better than their event-causal counterparts. I am grateful to Dale Tuggy, Patrick Todd, and an anonymous referee for raising this concern.

21 This of course assumes that the agent-causal power itself is possible. If one doubts that it is metaphysically possible to possess this power, then this point can be put thus: there is nothing about logical determinism per se that prevents agents from possessing (or exercising) the agent-causal power.
} 
that the causally complex event of Jones's fundamentally causing his decision to attend Yale could not be causally determined, or even caused for that matter (O’Connor 2000, p. 53). ${ }^{22}$ Let us refer to this kind of complex event as 'an agent-causal event.' Thus, the reason that possession of the agentcausal power is claimed to be incompatible with causal determinism is that it is metaphysically impossible for an agent-causal event to have a sufficient cause, or indeed any cause. ${ }^{23}$

But why think this? Consider again Jones's case in which he decides to attend Yale. Suppose that the motives favoring his attending Yale (his desires, beliefs, cares, etc.) make the probability associated with his exercising his agent-causal power to decide to attend Yale 1. Would it not then be plausible to conclude that it is possible that these motives cause Jones to make the decision? It is plausible to construe motives as exerting causal influence on agents. One might argue that the reason the probabilities associated with exercises of the agent-causal power are structured by the agent's motives is that these motives exert a causal influence on the agent to exercise the power in the relevant way. The deterministic case will, again, simply be the limiting one. In such a case the agent's motives will raise the probability of the agent's causing a certain decision to 1 because the motives deterministically cause the agent to make the decision.

\footnotetext{
22 If we endorse a component theory of action, then the contrast will not be between decisions per se and an agent's fundamentally causing a decision, but between events whose internal causal structure is exhausted by events causing other events and events whose internal causal structure includes substances fundamentally causing events. Recall that O'Connor endorses the event-causal theory of action. Given his component theory of action, he will say that a decision is an event with a certain internal causal structure, such as certain reasons causing an executive intention formation event. Rather than the reasons causing the decision, the decision consists in the reasons causing this special event. While O'Connor thinks, then, that decisions can be causally determined, he denies that an agent's fundamentally causing an event can be causally determined.

${ }^{23}$ Notice that this strategy for showing that an agent's possessing the agent-causal power is incompatible with determinism requires one to assume that an agent's fundamentally causing an event is itself an event. If one instead assumes that this entity is an abstract entity (such as a fact (Kim 1976, pp. 173-6)), then an agent's possessing the agent-causal power in a causally deterministic world is straightforwardly possible. After all, abstract entities are not happenings, and so the thesis of causal determinism does not require them to be caused, and so whether or not they are caused is irrelevant to whether an agent's possessing the agent-causal power is compatible with causal determinism. In order to consider the strongest case for thinking that possession of the agent-causal power is incompatible with causal determinism, I will assume that an agent's fundamentally causing an event is itself an event. I am grateful to Randy Clarke for raising this concern.
} 
Now we need to be careful here: what is the proposed causal effect of the motives? It cannot simply be Jones, for Jones is a substance and substances are not of the right category to be effects. Perhaps the effect is Jones's decision—event-causal models may opt for this interpretation. But there seems to be another possibility: namely that the motives causally influence Jones's making his decision - they cause the agent-causal event. Agent-causalists will want to insist not just that motives influence the occurrence of decisions, but that they influence the agent in his making a decision. And a natural way to analyse this last claim is that the motives causally influence the agent's fundamentally causing his decision. ${ }^{24}$ But this line of reasoning leads us to conclude that the agentcausal power is also compatible with causal determinism. If it is possible that motives structure probabilities associated with exercises of the agent-causal power by exerting causal influence on the agent, and if it is possible that these motives causally influence not just the decision but the agent's making the decision, then it seems possible for an agent-causal event to be causally determined. ${ }^{25}$

O’Connor, however, has argued that agent-causal events cannot be caused, and hence possession of the agent-causal power is incompatible with causal determinism (O'Connor 1995b, 2000, 2009). His argument unfolds by first considering how an event might cause a causally complex event that consists in an event's (rather than a substance's fundamentally) causing an event. For example, how might the lighting of a fuse cause the causally complex event of 'the dynamite's emitting a large quantity of hot gas [causing] the rapid dislocation of matter in its immediate vicinity' (O'Connor 2009, p. 196)? In such a case the lighting of the fuse causes this causally complex event by causing its first event-component, namely the dynamite's emitting a large quantity of hot gas (O’Connor 2009, p.

\footnotetext{
${ }^{24}$ Steward (2012, pp. 64-5) seems to accept this model of how motives causally interact with an agent's fundamentally bring something about. If one adopts a component theory of action, we can translate this point thus: motives do not just influence the occurrence of the effects that an agent fundamentally causes, they influence the agent's fundamentally causing these effects.

${ }^{25}$ Note that I do not need to show that this is the correct analysis of motivational influence. All I need to show is that it is metaphysically possible that motives so influence an agent, since what is at stake here is the compatibility of the possession of the agent-causal power and causal determinism.
} 
197; cf. O’Connor 1995b, 2000). The model we have then on which an event causes a causally complex event simply reduces to the event's causing the first event-component of the causally complex event. But this model cannot be applied to the agent-causal event. We cannot say then that the agent's motives cause the agent-causal event by causing the first component of this complex event since the first component is a substance, and substances cannot be effects. O'Connor concludes 'it is not clear that anything could (in strict truth) produce a causally-complex event of the form an agent's causing of intention I' (2009, p. 196). ${ }^{26}$

The problem with this argument is that it is too weak to establish its conclusion. O'Connor needs to show that it is metaphysically impossible for the agent-causal event to be caused. What he actually shows, however, is that a familiar model for explaining how an event causes a causally complex event cannot be applied to the agent-causal event. This establishes that it is metaphysically impossible for the agent-causal event to be caused only if this is the only possible model. O'Connor gives us no reason for thinking that it is the only model of how something (a substance or event) causes a causally complex event. So, at best, O'Connor's argument establishes that the agent-causal event cannot be caused in the way that merely causally complex events consisting wholly of events (and the causal relation) can be caused.

Not only is this conclusion too weak for O'Connor's purposes, it is also unsurprising: it is unsurprising that we find fundamental differences concerning the workings of fundamental substance-causation and fundamental event-causation. Only one with reductionist leanings would require that we model the causing of an agent-causal event along the same lines as we model the causing of a causally complex event wholly constituted by events. But agent-causalists reject this leaning and thus should be unmoved by the fact that fundamental substance-causation has different

${ }^{26}$ O'Connor originally claimed that it is 'strictly impossible' for an agent-causal event to be caused (1995b, p. 186; cf. 2000, p. 53), but seems now to have settled for this weaker conclusion. 
properties than event-causation. This difference is no barrier to conceiving of the agent-causal event's being caused. Again, to conceive of the agent-causal event being causally determined all one needs to imagine is that motives causally influence agents, and that they causally influence specifically the agent's fundamentally causing a certain choice. And we can readily conceive of this. ${ }^{27}$ I conclude, therefore, that exercises of the agent-causal power are compatible with logical and causal determinism, and therefore that the standard argument for the agent-causal theory fails. If Clarke and others are correct that agents who satisfy the agent-causal theory of free will possess more control than agents who merely satisfy the event-causal theory, and if this enhanced degree of control is necessary for free will and moral responsibility, then compatibilists can simply help themselves to the agent-causal theory. And this means that just as the only necessary difference between event-causal libertarianism and event-causal compatibilism is that the former theory requires indeterminism, so also the only necessary difference between agent-causal libertarianism and agent-causal compatibilism is that the former requires indeterminism. Thus, if the problem of enhanced control is a problem for some libertarians, it is a problem for all libertarians. ${ }^{28}$ Unlike other proponents of the standard argument, Clarke explicitly concedes that agents in worlds where logical or causal determinism obtain can possess the agent-causal power (2003, pp.

\footnotetext{
${ }_{27}$ This claim gains support from the growing literature on neo-Aristotelian accounts of causation (Molnar 2003; Lowe 2008; Jacobs 2011; Mumford and Anjum 2011; Heil 2012; Jacobs and O’Connor 2013; Swinburne 2013). On this view properties confer powers on substances and causation is the exercise of irreducible powers. Many (though not all (Mumford and Anjum 2011)) see substance-causation simply falling directly out of this account. Since causation is the manifestation of powers, and since substances are the bearers of powers, it seems, so the thought goes, that substances must be causes (Lowe 2008; Swinburne 2013). On this view a substance's manifesting a power is the substance's causing an effect. Consider a case of my punching a window that results in the window's breaking. I cause the window to break. On the present picture my causing the window to break consists in my manifesting various causal powers (moving my arm and so forth). But, one might argue, the event itself of the window's breaking consists in a substance's manifesting a power-namely the widow's manifesting its fragility (cf. Mumford and Anjum 2011). So on this analysis of my causing the window break, the event that I bring about is itself an event consisting of a substance-causing. Built into the very fabric of this metaphysics is the possibility of the agent- or, more broadly, substance-causal event being caused. And if the substance-causal event can be caused, I see no reason to deny the possibility that it can be deterministically caused. I am grateful to an anonymous referee for helping me see this connection.

${ }^{28}$ See Franklin 2011 where I offer a solution to this problem that both event-causal and agent-causal libertarians can endorse.
} 
163-3, 182). ${ }^{29}$ However, Clarke thinks that agent-causal libertarians still have a decided advantage over event-causal libertarians in solving the problem of enhanced control. In contrasting agentcausal libertarianism with agent-causal compatibilism, he writes:

the non-libertarian [agent-causal version] does not provide in any straightforward sense for agents' originating or initiating their actions. Such an account allows that each instance of agent-causation-if not itself causally determined by events that occurred long before the agent in question existed (and hence over which that agent has never had any control) - is made inevitable by these events as they causally determine the action that is agent-caused. In contrast, the libertarian [agent-causal] integrated account ... provides in a straightforward sense for agents' originating or initiating their free actions. Thus, the difference between what we get on the two accounts is not just that there is, only on the libertarian version, an absence of any determining causes of the actions that are said to be free. Because there is this absence, on the libertarian version alone, we get origination, in a straightforward sense, of actions by their agents. ${ }^{30}$ (Clarke 2003, p. 163)

Why does Clarke think that agent-causal libertarianism secures origination (and hence enhanced control), but agent-causal compatibilism does not? 'Because there is this absence'- that is, there is the absence of determinism on the former theory. But then indeterminism can, pace the standard argument, enhance control. Clarke argues in this passage that agent-causal libertarianism secures enhanced control vis-à-vis agent-causal compatibilism because it requires the presence indeterminism. But this flies in the face of Clarke's earlier objection to event-causal libertarianism, which assumed

${ }^{29}$ I am grateful to Randy Clarke for bringing these passages to my attention.

${ }^{30}$ Clarke allows that the agent-causal power is conferred on agents in a law governed way so that 'any agent who has that property when she acts agent-causes her action' (2003, p. 182). On this conception, if the action of an agent who possesses the agent-causal power is causally determined, then the agent's fundamentally causing her action is (logically? causally?) determined. 
that indeterminism cannot enhance control. When arguing that event-causal libertarianism fails to secure more control than event-causal compatibilism, Clarke writes:

The self-determination, ultimacy, origination, or initiation present with the second agent [who satisfies event-causal libertarianism] differs from that present with the first [agent who merely satisfies event-causal compatibilism] only by an absence: there is absent, with the second agent, other-determination, but there is not present any further sort of positive selfdetermination, any further exercise of a positive power to determine what one does. (Clarke 2003, p. 106)

Here Clarke argues that event-causal libertarianism secures no more control than event-causal compatibilism since the former theory fails to furnish agents with any new powers, but rather simply requires the absence of determinism. The problem for Clarke is that the difference between agentcausal libertarianism and agent-causal compatibilism also fits this description. Both agent-causal libertarianism and agent-causal compatibilism accord agents the power fundamentally to cause certain events (e.g. decisions). Agent-causal libertarianism differs from agent-causal compatibilism not in that it provides 'any further sort of positive self-determination, any further exercise of a positive power to determine what one does', but only in that it requires the absence of 'otherdetermination', such as determination by the past and laws of nature. But, then, if event-causal libertarianism cannot secure enhanced control vis-à-vis event-causal compatibilism because indeterminism cannot enhance control, then agent-causal libertarianism cannot secure enhanced control vis-à-vis agent-causal compatibilism.

This problem for Clarke bears out my claim that the success of the standard argument for agent-causal libertarianism requires us to assume that agents' possessing and exercising the agentcausal power is incompatible with determinism: for if this assumption is jettisoned, then agent-causal libertarianism, no less than event-causal libertarianism, must look to indeterminism as a control- 
enhancing feature. But if indeterminism can be control-enhancing, then perhaps event-causal libertarianism can secure more control than event-causal compatibilism, and so what reason then do we have for accepting the agent-causal theory of free will? ${ }^{31}$

\section{Putting the Self in Self-Determination}

Many may find the preceding conclusion congenial, perhaps confirmation of a long-standing suspicion that the agent-causal theory really has nothing going for it. But such a conclusion is premature. While the standard argument for the agent-causal theory is indeed flawed, there is a different source of motivation for this theory—one that I believe is both more powerful and broader in scope. We can be led to this source by reflecting upon the nature and role of the self in exercising free will.

Possessing free will requires possessing the power of self-determination-the power to intervene among one's various and often conflicting motivations and to determine which course of action to pursue (Watson 1987). The concept of self-determination under consideration here is further elaborated by J. David Velleman and Michael Bratman:

In a [self-determined] action, an intention is formed by the agent himself, not by his reasons for acting. Reasons affect his intention by influencing him to form it, but they thus affect his intention by affecting him first .... His role is to intervene between reasons and intention. (Velleman 1992, pp. 124-5)

\footnotetext{
${ }^{31}$ In section 5 below I return to the case for agent-causal libertarianism.
} 
The image of the agent directing and governing is, in the first instance, an image of the agent herself standing back from her attitudes, and doing the directing and governing. (Bratman 2005, pp. 195-6) $)^{32}$

Consider again the well-known case of a would-be thief deliberating about whether to rob a poor box at a local parish (van Inwagen 1983). He has reasons for both stealing and refraining from stealing. In favor of stealing, he has a great need of money, he knows he can get away with it, and he has easy access to the parish. In favor of refraining, he was recently struck by the vivid memory of promising his mother on her deathbed that he would live a good life. According to the event-causal theory of action, so long as one set of reasons (e.g. those favoring stealing) cause the corresponding behavioural events (e.g. those constituting stealing) in the appropriate manner, then the thief acts. On the event-causal theory of action, then, the agent's causal role is exhausted by the causal role of states and events, specifically motivational states and events.

Can the same be said of self-determination? Does self-determination simply consist in one's motivational states causing various mental episodes (e.g. decisions) and behavioural movements (e.g. stealing)? It seems not: for an agent to exercise the power of self-determination is for the agent to intervene among his various motivations for action and to determine how to act on their basis. And in order for the agent to be self-determining he must play these intermediary roles. But the thief is not identical to either his entire motivational composition or some subset of it: he is not his desires, cares, beliefs, intentions, plans, etc., nor is he some combination thereof. Therefore, if the only features of the thief relevant to bringing about his decision to steal are his motivations, then the thief himself does not determine what he does. But if the thief himself does not determine what he does,

\footnotetext{
32 In case one worries that these descriptions of self-determination stack the deck against either reductionists or compatibilism, Watson, Velleman, and Bratman all argue that this notion of self-determination is compatible with reductionism and determinism. I am grateful to Andy Cullison for noting the importance of making this point explicit.
} 
then he does not exercise his power of self-determination. It follows from this that exercises of the power of self-determination are not reducible to the causal activity of states and events.

Stated more formally, the argument runs as follows:

(1) An agent $s$ self-determines a decision $d$ only if (i) $s$ adjudicates between his various motivations for or against $d$, and (ii) on the basis of this adjudicating process $s$ determines or causes $d$.

(2) If the members of some set of states and events play the causal roles of (i) and (ii), then $s$ plays the causal roles of (i) and (ii) only if $s$ is identical to (some members of) this set of states and events.

(3) An agent is not identical to any state or event or any set of states and events.

(4) Therefore, if the members of some set of states and events play the causal roles of (i) and (ii), then $s$ does not self-determine $d$.

(5) Therefore, if $s$ self-determines $d$, then $s$, and not merely states and events, causes $s$.

Let's call this The It Ain't Me Argument, as it contends that if only states and events cause my decisions, then 'it ain't me' that causes my decision, and thus $I$ do not self-determine what I do. The first premiss is about the nature of self-determination. According to this premiss, the concept of a self-determining agent is first and foremost the concept of the agent playing a causal role in the genesis of action. ${ }^{33}$ Furthermore, this concept affords the agent a specific causal role-namely one of adjudicating between his various motivations for action and making a decision on the basis of this adjudication. What exactly this process of adjudication amounts to is controversial: perhaps this process requires agents to rationally reflect on these various motivations (Velleman 1992), or to form higher-order desires about which motivation they want to be effective in action (Frankfurt 1971), or to weigh carefully which course of action they most value (Watson 1975) or care most about (Shoemaker 2003), or what their self-governing policies direct concerning how to treat these various motivations (Bratman 2000). But whatever else this process of adjudication is, it is a process in which the agent considers his various motivations for action and selects which course of action to pursue. Thus, the self-determining agent plays a causal role over and above the causal role played by

\footnotetext{
${ }^{33}$ That the concept of self-determination is a causal concept is one of the most widely agreed upon premises in the free will literature, although there are important dissenters. See Ginet 1990, McCann 1998, Goetz 2009.
} 
his specific motivations for action: he must intervene among these motivations and decide which ones to act on. The second premiss states that in order for an agent to exercise his power of selfdetermination he must play this distinctive causal role: the role of the agent cannot be played by something other than him. After all, if the agent's causal roles are played by something else (e.g. states and events), then how can we say be is playing them? Thus, if the agent's causal roles are played by states and events, then he must be identical to (some of) these states and events. But the third premiss denies that the agent is identical to any set of states and events, and hence the agent is not identical to either a single motivation or collection of motivations. It follows from these premises that the agent himself, which is a substance, not a state or event (or set of states and events), must be fundamentally causally involved in the production of a choice in order to exercise his power of self-determination. ${ }^{34}$

One might think that exercising the power of self-determination is not strictly necessary for performing a free action. Consider the weak-willed agent. When he acts weakly, it may seem that rather than intervening among his various motivations and determining how to act, he is often moved to action despite his determination concerning what to do, or at least in its absence. ${ }^{35}$ But weak-willed agents can act freely. So it might seem that there can be cases in which an agent fails to exercise his power of self-determination and yet still acts freely. Nevertheless, even in these cases we

\footnotetext{
34 When arguing that agent-causal libertarianism has decided advantages over event-causal libertarianism for solving the problem of enhanced control, Clarke contends that on event-causal libertarianism 'we do not get an origination or initiation of actions by their agents in anything other than a figurative or interest-relative sense' (2003, p. 164). Clarke does not explain or defend this claim, nor does he indicate how it fits with his earlier objection that event-causal libertarianism cannot secure enhanced control since it differs from event-causal compatibilism only by way of adding indeterminism. None the less, this passage suggests that Clarke may have had in mind the kind of argument that I am offering. If this is indeed what Clarke had in mind, then I am in agreement with him, and hope to have brought this point out more forcefully.

Markosian argues that the intuition that the agent-causal theory is based on is not 'a genuinely incompatibilist intuition. Rather, it is based on [the] intuition ... that you cannot be morally responsible for an action that is caused by something outside of you, but not caused by you ...' (1999, p. 270). While Markosian does not unpack this claim, it strikes me as close to what I have been arguing.

${ }^{35}$ Compare Tolstoy's description of Evgeny Irtenev: 'And suddenly passionate lust seared him, clutching his heart like a hand. As if by someone else’s alien will, Evgeny glanced around and went after them’ (1889, p. 188).
} 
think that the weak-willed agent acted freely only if he could have exercised his power of selfdetermination-only if he could have utilized this power to pursue the course of action that he judged best (cf. Velleman 1992, p. 127 n. 13). So while every exercise of free will may not require the exercise of the power of self-determination, exercising free will at least requires the possibility of exercising the power of self-determination. And according to the above argument, in order for it to be possible for the agent to exercise the power of self-determination, it must be possible that the agent as substance, rather than simply some state or event of the agent, be causally involved. ${ }^{36}$

The It Ain't Me Argument is, I submit, the real motivation for the agent-causal theory of free will. Observe that there is nothing about this argument that depends on views concerning the (in)compatibility of free will and determinism. The argument is independent of these issues and thus has import for both compatibilists and incompatibilists alike. The issue here is not the existence or relevance of determinism or indeterminism, but reductionism: can the agent or the agent's role in self-determination be reduced to the role of states and events? Proponents of the agent-causal theory argue for a negative answer, contending that exercising the power of self-determination requires that the agent be fundamentally causally involved in the production of the decision.

Now that we have unveiled the central reason for the agent-causal theory, we can see both how this theory is of broader scope and more attractive than it might have otherwise seemed. ${ }^{37}$

\footnotetext{
${ }^{36}$ If one does adopt this view, then we are forced to rewrite the statement of the agent-causal theory above along the lines mentioned in n. 1. According to my current statement of the theory, an action is directly free only if the agent fundamentally causes the action. If we are to allow for weak-willed actions that are both directly free and yet not fundamentally caused by the agent, then we must qualify this statement, allowing that agents can perform directly free actions even if they do not fundamentally cause them, so long as the agents could have brought their agent-causal power to bear in certain ways. I am grateful to Neal Tognazzini for bringing this issue to my attention.

${ }^{37}$ Someone may be motivated to embrace the agent-causal theory of free will because they are after a certain kind of counter-deterministic power: one that is incompatible with both reductionism and determinism. In this sense their reason for accepting the agent-causal theory of free will is not nonpartisan-it is not a reason that compatibilists can also accept. However, my claim is that any argument that such a counter-deterministic power is necessary for free will must have two logically distinct parts. One part must show that the relevant power must been understood along the lines of the agent-causal theory of free will and not the event-causal theory. The other part must show that exercises of this power, at least free exercises, must be undetermined. The first part of the argument has to do with worries about mechanism or reductionism and the second part with worries about determinism. The crucial thing to realize is that these worries can and do come apart. If there is an argument showing that reductionism really is incompatible with free
} 
There are two general lines of resistance to the agent-causal theory. First, one can argue that the agent is literally identical to the collection (or some subset) of his motivations. Let us call such theorists 'identity reductionists about self-determination', since they embrace a broadly Humean view of the self (Hume 1740, p. 252; Campbell 2000, 2006), denying (3). Second, one can argue that while the agent is not literally identical to any state or event, or collections thereof, the agent's role is played by such states and events. That is, one can argue that an agent's exercising the power of selfdetermination is reducible to the causal interplay among states and events involving the agent. Now such a response may seem immediately doomed to failure as the concept of a self-determining agent is one of the agent playing a causal role over and above the causal role played by his specific motivations. Moreover, since the agent is not literally identical to any of these states and events, it may seem puzzling how their playing his role can count as his playing his role. But reductionists of this stripe have sophisticated responses. First, they contend that although the agent is not literally identical to his motivations, some of the agent's attitudes have authority to speak for the agent because the agent is identified with them (Frankfurt 1971, 1987, 1993, 1994; Watson 1975; Velleman 1992; Ekstrom 2000; Bratman 2000, 2005; Shoemaker 2003; Jaworska 2007). When an agent is identified with any such attitude, the attitude can stand proxy for the agent and in this way the attitude's playing the agent's role counts as his playing his role. Second, they contend that these special attitudes (unlike the agent's specific motivations) play the causal role of the self-determining agent, adjudicating between and determining a decision on the basis of the agent's other motivations. Such theorists, who we can call 'identification reductionists about self-determination', deny (2) and

\footnotetext{
will, then compatibilists can accept this. What compatibilists must reject, whether they embrace reductionism or nonreductionism, is that exercises of free will must be undetermined. So while someone's ultimate motivation for accepting the agent-causal theory might be to articulate the idea of a counter-deterministic power, any argument that this power must be analysed along agent-causal (opposed to event-casual) lines will be nonpartisan: if it shows that incompatibilists should embrace the agent-causal theory, it also shows that compatibilists should embrace this theory. I am grateful to an anonymous referee for pressing me to make this point clear. See section 5 below where I further develop this point.
} 
contend that the agent can count as playing a distinctive causal role even if his causal role is played by states and events that are not identical to him, so long as these are states and events with which he is identified.

There are two broad possibilities when seeking to analyse the power of self-determination: reductionism or nonreductionism. Reductionists must endorse either Humeanism about the self or a theory of identification about agency. Therefore, proponents of the existence of free will must either accept the agent-causal theory of free will, Humeanism about the self, or an identification theory of agency. When placed in this light, we see that that main motivation for the agent-causal theory is broader in scope and more powerful than we might otherwise have thought. Any compatibilist who has antireductionist sympathies cannot avail himself of the agent-causal theory under the standard argument. According to that argument, only libertarians (incompatibilists more generally) can endorse the agent-causal theory. But now we have come to see that the true reason to endorse the agent-causal theory is to avoid reductionism about the self and self-determining agency. This opens the possibility of the agent-causal theory being accepted even by compatibilists, and in this way allows the theory to be of broader scope. Furthermore, there are powerful objections to both Humeanism about the self and identification theories, and thus the alternatives to the agent-causal theory are questionable. ${ }^{38}$ Now, of course, many have contended that there are powerful objections to the agent-causal theory itself, and so perhaps in the end this theory will turn out to be no less (or

\footnotetext{
${ }^{38}$ I do not mean to suggest that these theories are known to be false, but only that they are known to face serious objections. Consider Watson's conclusion concerning identification theories: 'We are left with a rather elusive notion of identification and thereby an elusive notion of self-determination. The picture of identification as some kind of brute self-assertion seems totally unsatisfactory, but I have no idea what an illuminating account might be' (1987, p. 169). For subsequent attempts to provide illuminating accounts of identification see Velleman 1992, Frankfurt 1993, 1994, Bratman 2000, 2005, Ekstrom 2000, Shoemaker 2003, and Jaworska 2007. In Franklin n.d. I survey all these accounts and argue that they fail.

Perhaps the most significant objection to neo-Humean (or bundle) theories of the self concerns their apparent incapacity to draw the proper boundary between essential and non-essential properties of the self (see Olson 2007, chapter 6) for critical discussion of the bundle view). For important recent defenses of the bundle theory see Campbell $2000,2006$.
} 
even more) problematic than the alternatives. But my suspicion is that many philosophers, when faced with these questionable alternatives, will give the agent-causal theory a second look.

\section{Agent-Causal Libertarianism}

By way of conclusion I want to return to the case for agent-causal libertarianism. I have sought to defend three claims in this paper. First, I argued that the standard argument for the agent-causal theory of free will fails, since possession of the agent-causal power is compatible with both logical and causal determinism. Second, I argued that the real motivation for the agent-causal theory is nonpartisan. The reason to accept the agent-causal theory of free will is that neither the agent himself is reducible to states and events nor is his role in self-determination reducible to the causal activities of states and events. The real issue motivating acceptance of this theory concerns neither determinism nor indeterminism, but reductionism. Hence, if anyone should be an agent-causalist, then everyone should be an agent-causalist. Third, I argued that an appreciation of the true motivation for the agent-causal theory reveals it to be broader in scope and more powerful than it otherwise may have seemed.

How do these conclusions affect the case for agent-causal libertarianism? They end up, I believe, shifting and multiplying the sources of opposition to this theory. Agent-causal libertarians usually focus their critical attention on event-causal libertarians, contending that indeterminism cannot be control enhancing. However, we have seen that agent-causal libertarians cannot make this claim—otherwise they end up undermining their own position in favor of agent-causal compatibilism. The issue between agent-causal and event-causal libertarianism has, thus, shifted from whether indeterminism is control enhancing (both positions are committed to indeterminism's being control enhancing) to the issue of whether reductionism or nonreductionism about either the self or self-determining agency is correct. To refute event-causal libertarianism, agent-causal 
libertarians need to show that we must opt for a nonreductionist theory of the self and selfdetermining agency. ${ }^{39}$ But even if agent-causal libertarians can establish the truth of a nonreductionist theory, they have yet to show that we should be agent-causal libertarians. The source of opposition to agent-causal libertarianism has multiplied: agent-causal libertarians must also refute agent-causal compatibilism. The issue between these theorists is whether indeterminism enhances control and whether this enhanced degree of control is necessary for free will. It is important to realize that agent-causal libertarianism must establish both that indeterminism enhances control and that this enhanced degree of control is necessary for free will: for if they can only show that indeterminism enhances control, then it is open to agent-causal compatibilists to concede this and yet simply deny that this enhanced degree of control, although perhaps desirable, is necessary for freedom.

Establishing agent-causal libertarianism, then, depends on establishing three conclusions: (i) that exercises of the power of self-determination requires that agents qua substances be fundamentally causally involved in the production of their decisions, (ii) that indeterminism enhances control, and (iii) that this enhanced degree of control is necessary for free will. Agentcausal libertarians (and incompatibilists more generally) have spent much time trying to show that the kind of control necessary for freedom can only be secured if indeterminism obtains. They have, however, spent little to no time directly defending nonreductionism about the self and selfdetermining agency. I think this lacuna in their defenses is doubly problematic. First, in failing to directly defend their nonreductionism, they fail to address the central tenet of their theory: namely that the causal role of the agent in self-determination is not reducible to the causal role of states and events. Second, by failing to address this central tenet, they also leave obscure the most attractive

\footnotetext{
${ }^{39}$ Most event-causal libertarians also fail to address the issue of reductionism head on. Ekstrom 2000 is an important exception to this rule, as she defends an identification reductionist model of libertarianism. See also Franklin 2014 where I develop an identification reductionist model of libertarianism.
} 
feature of their theory: namely avoidance of reductionism about the self and self-determining agency. It is time then that agent-causal libertarians and their critics face up to difficulties surrounding the nature and role of the self in exercises of free will—only then can we establish or confidently lay to rest the agent-causal theory of free will. ${ }^{40}$

${ }^{40}$ Earlier versions of this paper were presented at 2013 Pacific Division Meeting of the American Philosophical Association and the Young Philosophers Lecture Series at SUNY, Fredonia. I am grateful to the audiences for their instructive feedback, especially Andrew Bailey, Mark Balaguer, Andy Cullison, Neil Feit, Michael McKenna, Rebekah Rice, and Dale Tuggy. Thanks to Randy Clarke, John Fischer, Dana Nelkin, Garrett Pendergraft, Derk Pereboom, Patrick Todd, and Neal Tognazzini for feedback that made this paper considerably better. I also want to thank two anonymous referees and the Editor of this journal for their helpful feedback 


\section{Bibliography}

Binkley, Robert, Richard Bronaugh, and Ausonio Marras (eds) 1971: Agent, Action, and Reason. Toronto: University of Toronto Press.

Bishop, John 1986: 'Is Agent-Causality a Conceptual Primitive?’ Synthese, 67, pp. 225-47.

1989: Natural Agency: An Essay on the Causal Theory of Action. Cambridge: Cambridge University Press.

Brand, Myles 1979: 'The Fundamental Question in Action Theory'. Noûs, 22, pp. 131-51.

1984: Intending and Acting: Toward a Naturalized Action Theory. Cambridge, MA: MIT press.

Brand, Myles, and Douglas Walton (eds) 1976: Action Theory. Dordrecht: D. Reidel Publishing Co.

Bratman, Michael 2000: 'Reflection, Planning, and Temporally Extended Agency', in his 2007, pp. 21-46. Originally published in Philosophical Review, 109, 2000.

2005: 'Planning Agency, Autonomous Agency', in his 2007, pp. 195-221. Originally published in Taylor 2005.

2007: The Structure of Agency: Essays. New York: Oxford University Press.

Campbell, Scott 2000: 'Could Your Life Have Been Different'. American Philosophical Quarterly, 37, pp. 37-50.

2006: 'The Conception of a Person as a Series of Mental Events'. Philosophy and Phenomenological Research, 73, pp. 339-58.

Chisholm, Roderick 1966: 'Freedom and Action'. In Lehrer 1966, pp. 11-44.

Clarke, Randolph 1995: 'Indeterminism and Control'. American Philosophical Quarterly, 32, pp. 125-38.

2000: ‘Modest Libertarianism'. Philosophical Perspectives, 14, pp. 21-45.

2003: Libertarian Accounts of Free Will. New York: Oxford University Press.

Davidson, Donald 1963: 'Actions, Reasons, and Causes', in his 1980, pp. 3-20. Originally published in Journal of Philosophy, 60, 1963.

1971: 'Agency', in his 1980, pp. 43-62. Originally published in Binkley, Bronaugh, and Marras 1971. Toronto: University of Toronto Press.

-1973: 'Freedom to Act', in his 1980, pp. 63-82. Originally published in Honderich 1973.

1980: Essays on Actions and Events. Oxford: Clarendon Press. 
Earman, John 1986: A Primer on Determinism. Dordrecht: Springer.

Ekstrom, Laura Waddell 2000: Free Will: A Philosophical Study. Boulder, CO: Westview Press.

Enç, Berent 2003: How We Act: Causes, Reasons, and Intentions. New York: Oxford University Press.

Fischer, John Marin 1994: The Metaphysics of Free Will. Oxford: Blackwell Publishers.

Fischer, John Martin, Robert Kane, Derk Pereboom, and Manuel Vargas 2007: Four Views on Free Will. Malden: Blackwell Publishing.

Frankfurt, Harry 1971: 'Freedom of the Will and the Concept of a Person', in his 1988, pp. 11-25. Originally published in Journal of Philosophy, 68, 1971.

-1987: 'Identification and Wholeheartedness', in his 1988, pp. 159-76. Originally published in Schoeman 1987.

-1988: The Importance of What We Care About. New York: Cambridge University Press.

-1993: 'On the Necessity of Ideals', in his 1999, pp. 108-16. Originally published in Noam and Wren 1993.

-1994: 'Autonomy, Necessity, and Love', in his 1999, pp. 129-41. Originally published in Fulda and Horstmann 1994.

1999: Necessity, Volition, and Love. New York: Cambridge University Press.

Franklin, Christopher Evan 2011: 'The Problem of Enhanced Control'. Australasian Journal of Philosophy, 89, pp. 687-706.

2014: 'Event-Causal Libertarianism, Functional Reduction, and the Disappearing Agent Argument'. Philosophical Studies, 170, pp. 413-432.

n.d.: 'Identification, Self-Determination, and Reductionism'.

Fulda, H.F., and R.P. Horstmann (eds) 1994: Vernunftbegriffe in der Moderne: Stuttgarter Hegel-Kongress 1993. Stuttgart: Klett-Cotta.

Gibb, S. C., E. J. Lowe, and R. D. Ingthorsson (eds) 2013: Mental Causation and Ontology. Oxford: Oxford University Press.

Ginet, Carl 1990: On Action. New York: Cambridge University Press.

Goetz, Stewart 2009: Freedom, Teleology, and Evil. London: T\&T Clark.

Goldman, Alvin 1970: A Theory of Human Action. Princeton, N.J.: Princeton University Press.

Handfield, Toby (ed.) 2009: Dispositions and Causes. Oxford: Oxford University Press. 
Heil, John 2012: The Universe as We Find It. New York: Oxford University Press.

Honderich, Ted (ed.) 1973: Essays on Freedom of Action. New York: Routledge and Kagam Press.

Hume, David 1740 (1978): A Treatise of Hume Nature, 2nd edition, eds. L.A. Selby-Bigge and P.H. Nidditch. Oxford: Oxford University Press.

Kane, Robert 1996: The Significance of Free Will. New York: Oxford University Press.

Kim, Jaegwon 1976: 'Events as Property Exemplifications'. In Brand and Walton 1976, pp. 159-77.

Jaworska, Agnieszka 2007: 'Caring and Internality'. Philosophy and Phenomenological Research, 74, pp. 529-68.

Jacobs, Jonathan D. 2011: 'Powerful Qualities, not Pure Powers'. The Monist, 94, pp. 81-102.

Jacobs, Jonathan D., and Timothy O’Connor 2013: 'Agent Causation in a Neo-Aristotelian

Metaphysics’. In Gibb, Lowe, and Ingthorsson 2013, pp. 173-92.

Lehrer, Keith (ed.) 1966: Freedom and Determinism. New York: Random House.

Lowe, E.J 2008: Personal Agency: The Metaphysics of Mind and Action. Oxford: Oxford University Press.

Markosian, Ned 1999: 'A Compatibilist Version of the Theory of Agent Causation'. Pacific

Philosophical Quarterly, 80, pp. 257-77.

2012: 'Agent Causation as the Solution to all the Compatibilist's Problems'. Philosophical Studies, 157, pp. 383-98.

McCann, Hugh J. 1998: The Works of Agency: On Human Action, Will, and Freedom. Ithaca, NY: Cornell University Press.

Mele, Alfred R. 1992: Springs of Action. New York: Oxford University Press.

Molnar, George 2003: Powers: A Study in Metaphysics. Oxford: Oxford University Press.

Mumford, Stephen, and Rani Lill Anjum 2011: Getting Causes from Powers. Oxford: Oxford University Press.

Nelkin, Dana Kay 2011: Making Sense of Freedom and Responsibility. New York: Oxford University Press.

Noam, G.C., and T. Wren (eds) 1993: The Moral Self. Cambridge, MA: MIT Press.

O'Connor, Timothy 1993: 'Indeterminism and Free Agency: Three Recent Views'. Philosophy and Phenomenological Research, 53, pp. 499-526. 
O’Connor, Timothy (ed.) 1995a: Agent, Causes, and Events: Essays on Indeterminism and Free Will. New York: Oxford University Press.

_1995b: ‘Agent Causation’. In O’Connor 1995a, pp. 173-200.

2000: Persons and Causes: The Metaphysics of Free Will. New York: Oxford University Press.

2005: 'Freedom with a Human Face'. Midwest Studies in Philosophy, 29, pp. 207-27.

_2009: ‘Agent-causal power’. In Handfield 2009, pp. 189-214.

Olson, Eric 2007: What Are We? Oxford: Oxford University Press.

Pereboom, Derk 2001: Living without Free Will. New York: Cambridge University Press.

_2004: 'Is Our Conception of Agent-Causation Coherent?' Philosophical Topics, 32, pp. 275-86.

-2007: 'Hard Incompatibilism'. In Fischer, Kane, Pereboom, and Vargas 2007, pp. 85-125.

Schlosser, Markus Ernst 2008: 'Agent-causation and Agent Control'. Philosophical Explorations, 11, p. 3-21.

Schoeman, Ferdinand David (ed.) 1987: Responsibility, Character, and the Emotions: New Essays in Moral Psychology. Cambridge: Cambridge University Press.

Shoemaker, David 2003: 'Caring, Identification, and Agency'. Ethics, 114, pp. 88-118.

Taylor, James Stacey (ed.) 2005: Personal Autonomy. New York: Cambridge University Press.

Steward, Helen 2012: A Metaphysics for Freedom. Oxford: Oxford University Press.

Stump, Eleonore 1999: 'Alternative Possibilities and Moral Responsibility: The Flicker of Freedom'. Journal of Ethics, 3, pp. 299-324.

Taylor, Richard 1966: Action and Purpose. Englewood Cliffs, N.J.: Prentice Hall.

Tolstoy, Leo 1889: 'The Devil', in his 2010, pp. 164-208.

Tolstoy, Leo 2010: The Death of Ivan Ilyich \& Other Stories. Trans. Richard Pevear and Larissa Volokhonsky. New York: Vintage Classics.

van Inwagen, Peter 1983: An Essay on Free Will. Oxford: Clarendon Press.

Velleman, J. David 1992: 'What Happens When Someone Acts?', in his 2000, pp. 123-43. Originally published in Mind, 101, 1992.

2000: The Possibility of Practical Reason. New York: Oxford University Press. 
Watson, Gary 1975: 'Free Agency', in his 2004, pp. 13-32. Originally published in Journal of Philosophy, 72, 1975.

1987: 'Free Action and Free Will', in his 2004, pp. 161-96. Originally published in Mind, 96, 1987.

1999: 'Soft Libertarianism and Hard Compatibilism', in his 2004, pp. 197-215. Originally published in Journal of Ethics, 3, 1999.

2004: Agency and Answerability: Selected Essays. New York: Oxford University Press.

Zagzebski, Linda 2000: 'Does Libertarian Freedom Require Alternative Possibilities?’ Philosophical Perspectives, 14, pp. 231-248.

Swinburne, Richard 2013: Mind, Brain, and Free Will. Oxford: Oxford University Press. 